\title{
Quantitative Analysis For the Vehicle Moment of Inertia and Physical Simulation
}

\author{
Wenming Yu \\ School of Traffic Engineering, Huaiyin Institute of Technology, Jiangsu, Huaian, 223003,China
}

124577826@qq.com

Keywords: Vehicle; moment of inertia; quantitative analysis; physical simulation

\begin{abstract}
With the development of computer and electronic technology, instead of the traditional flywheel technology, electronic simulation technology helps to achieve the simulation and analysis for automotive mechanical inertia. According to the experience of many years of study and practice, this paper analyzed the vehicle inertia electrical simulation technology, and then conducted a physical simulation model based on kinetic theory. Simulation results show that the control method is feasible. The research results play a guiding role for car performance testing and design.
\end{abstract}

\section{Introduction}

The modern automobile industry is undergoing tremendous change, and dramatically to increase production puts forward higher requirements for the car quality performance. In addition, the new technology quickly puts into use, vehicle model changes with each passing day, which put forward higher requirements for automotive testing technology, and it should be able to test the vehicle performance in a short period of time, providing reliable data for the use of a new vehicle research and new technologies. In a variety of automotive test systems, there is a common technical aspects, that is automotive mechanical inertia simulation, while, most of the time, the vehicle testing is per

\section{Electrical simulation technology of automotive mechanical inertia}

The core content to conducted automotive mechanical inertia test by the use electrical simulation technology includes the following two core content: The first is to determine the basic inertia of the vehicle, because the inertia generated by different vehicles is quite different, and the inertia generated by the same vehicle is not the same in different test project. The second, electrical simulation technology requires the use of electric drive systems, through precise control of the output torque to adjust the vehicle acceleration and speed during acceleration and deceleration. The above parameters can be measured by torque, and thus the core electrical simulation technology is torque control.

\section{Determination of vehicle inertia}

Simulation of mechanical inertia first requires a quantitative analysis of inertia, and then determine the structure of the system according to the test objectives and requirements. we can take advantage of special test equipment to measure the car's mechanical inertia or use some of the technical documentation to obtain the relevant data. As the measure vehicle drive axle drive, as long as get the quality and the wheel radius of the vehicle, we can use the formula to obtain the relevant mechanical inertia.

\section{Motion control of simulation system}

In the electric simulation, when the engine starts driving, all components and load cars have become its load, when using electrical inertia to simulate load, we should make the electrical inertia of the vehicle speed is consistent with real operating conditions, so as to ensure the authenticity of the simulation. If the simulated vehicle mass is larger, both in acceleration or deceleration phase, acceleration electrical inertia of the system should also be consistent with the actual operation of vehicles. Assuming electric system inertia movement pattern conforms to the following equation: 


$$
T-T_{L}=J \frac{\mathrm{d} \omega}{\mathrm{dt}}
$$

In this formula, $T$ represents the engine output torque, $\mathrm{N} / \mathrm{m} ; \mathrm{T}_{\mathrm{L}}$ represents the load torque, N/m; $\mathrm{J}$ represents the mechanical moment of inertia, $\mathrm{kg} / \mathrm{m}^{2} ; \omega$ represents the angular speed, $\mathrm{rad} / \mathrm{s} ; \mathrm{d} \omega / \mathrm{dt}$ represents the angular acceleration, $\mathrm{rad} / \mathrm{s}^{2}$.

Electrical inertia system equations of motion as follows:

$$
T-T_{L}+T_{C}=J_{1} \frac{\mathrm{d} \omega}{\mathrm{dt}}
$$

In this formula, $T_{C}$ represents the electromagnetic torque produced by the motor load, $\mathrm{N} / \mathrm{m} ; \mathrm{J}_{1}$ represents the system mechanical moment of inertia, $\mathrm{kg} / \mathrm{m}^{2}$. Further it can be drawn:

$$
T_{\mathrm{e}}=\left(T-T_{L}\right)\left(\frac{1}{K}-1\right)
$$

In this formula, $\mathrm{K}$ represents a multiple of inertia simulation. By the above discussion, the following conclusions can be drawn:

(1) In the acceleration phase, if $\left(T-T_{L}\right)>0$, and automotive mechanical inertia is large, while the mechanical inertia electrical inertia of the system is relatively small, ie $\mathrm{K}$ value is greater than 1 , the $\mathrm{T}_{\mathrm{C}}$ is less than zero, in this case, the actual motor speed and torque load in the opposite direction, thus preventing cars accelerate motion. (2) In the vehicle deceleration phase, the situation is just the opposite, since $T_{e}$ is greater than zero, the actual motor speed and torque load is same, thus preventing cars decelerate movement.

\section{Electrical inertia control}

Taking AC motor frequency converter as a starting point, by means of electrical AC variable speed control AC motor inertia mechanical properties, the equation is as follows:

$$
T_{\mathrm{e}}=\frac{2 \mathrm{ps}_{2} U_{2}^{1}}{2 \pi \mathrm{f}_{1}\left[\left(s r^{1}+r_{2}^{\prime}\right)^{2}+s^{2}\left(x_{\sigma 1}+x_{\sigma 2}^{\prime}\right)^{2}\right]}
$$

In the formula, $\mathrm{p}$ represents the number of pole pairs of the motor, $\mathrm{kW}$; $\mathrm{s}$ represents slip; $\mathrm{r}_{1}$ represents the motor stator resistance, $\Omega ; r_{2}$ represents the equivalent resistance of the rotor, $\Omega$; $\mathrm{U}_{1}$ represents the motor terminal voltage, $\mathrm{V} ; \mathrm{f}_{1}$ represents the output frequency, $\mathrm{Hz} ; \mathbf{X}_{\sigma 1}$ represents that the motor stator reactance, $\Omega ; \mathbf{X}_{\sigma 2}{ }^{\prime}$ represents the equivalent motor rotor reactance, $\Omega$.

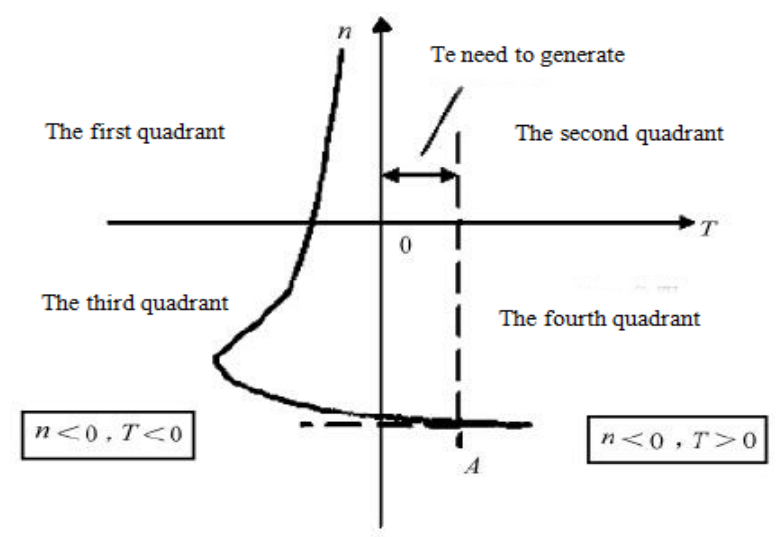

Fig.1 AC motor inverter system mechanical characteristics (vehicle acceleration phase)

For AC motor frequency converter, we can achieve the purpose of changing the motor speed by varying the power frequency. When using a constant power ratio control mode, while in control of the inverter output power, it needs to control and maintain a constant voltage output. When the speed increases, the electromagnetic torque generated by the motor torque load is impedance, which is opposite to the direction of the torque ( Figure 1).

At this time, the load motor operating point of the point $\mathrm{A}$ in the mechanical properties should be 
in the 4th quadrant of the curve, and it can generate system test torque requiredt $\mathrm{T}_{\mathrm{c}}$, which data may be calculated using the mathematical methods, real motor speed can be measured by the device. At this point, the working status of the AC motor for regenerative braking state, the actual speed is greater than the synchronous speed, you can use the following formula to determine the output frequency.

$$
\mathrm{f}=\frac{2 \mathrm{r}_{2} \pi}{3 \mathrm{p} \mathrm{K}^{2}} T_{\mathrm{e}}+\frac{\mathrm{p}}{60} \mathrm{n}
$$

In this formula , $\mathrm{n}$ represents motor rotational speed, $\mathrm{r} / \mathrm{min}$.

Construct a controller according to the formula in claim 2, controls the frequency of the inverter will get compensation torque, thereby controlling the electrical inertia of the system acceleration, complete change of mechanical inertia simulation. Due to the changing electromagnetic torque and speed, the drive frequency also changes in real time, so the use of electrical inertia simulation system consisting of analog technology is a dynamic system.

\section{Physical simulation experiment}

According to kinetic model theory, the speed motor output shaft as a control volume, the braking torque as feedback, the specific process is as follows:

After braking start, collect braking torque signal via moment sensor, data acquisition card, the digital signal input into the computer calculates the required speed, and then through the A / D conversion to an analog signal to the motor speed controller for motor speed control. The test is done in the inertial bench, electrical analog system uses dual closed-loop control system, using the moment of inertia of $20.48 \mathrm{~kg} / \mathrm{m}^{2}$ small flywheel to simulate a series of large flywheel moment of inertia. Rotational speed is set and $1000 \mathrm{r} / \mathrm{min}$ and $700 \mathrm{r} / \mathrm{min}$, constant torque is set at $400-500 \mathrm{~N} / \mathrm{m}$, the test results shown in Figure 2.

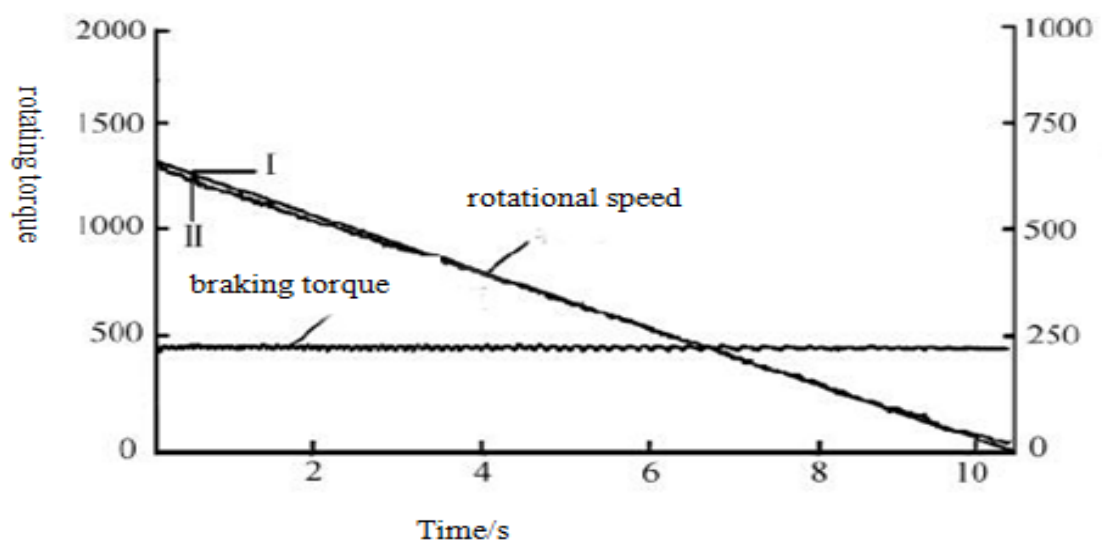

Fig.2 The moment of inertia simulation $20.48 \mathrm{~kg} / \mathrm{m}^{2}$ small flywheel for $80 \mathrm{~kg} / \mathrm{m}^{2}$ large flywheel As can be seen from Figure 2, electrical analog system operation showed control law dual-loop control system, constant torque has some fluctuations, for the dual closed-loop system. It is slightly disturbing effect, which will simulate a slight curve fluctuations. In addition, the electrical analog system error is relatively larger than the test run in the middle section in the run at the beginning and end, which is mainly caused by sudden load system lag and free parking when you run begins and ends.

\section{Conclusion}

Automotive electrical mechanical inertia simulation technology can test the performance of the car and provide basic data for the design, and electric cars inertia simulation system has characteristics of flexible adjustment, high degree of automation, simple device and easy to maintain, therefore, this technology will become a mainstream technology for the automotive performance testing. 


\section{References}

[1] Xu Xiaoming, Liu Shuli, Gu Guohua. Coupling Analysis of Moment of Inertia \&amp; Dynamic on Optoelectronic Tracking Turntable[J]. Journal of Scientific Instrument, 2013, S1: 214-218.

[2] Hou Wen, Zheng Bin, Yang Ruifeng. A Measuring Method on Moment of Inertia of Large-scale Ammunition[J]. Journal of China Ordnance,2005,01:41-45.

[3]Zhu Yunpu Zhang Mingming (School of Mechanical Engineering, Nanjing University of Science and Technology, Nanjing, 210094 China). Design of Hardware and Software for the Projectile's Moment of Inertia Measurement System[A]. Chinese Institute of Electronics .ICEMI'2005 Seventh International Conference on Electronic Measurement and Instrument Proceedings [C] Chinese Institute of Electronics: 2005: 4.

[4] Mo Zhiyong, Zhang Weigong. Automotive electrical mechanical inertia simulation technology [J]. Chinese Inertial Technology, Jan. 2009: 123-126.

[5] T.Koyama,M.Chijimatsu,H.Shimizu,S.Nakama,T.Fujita,A.Kobayashi,Y.Ohnishi. Numerical modeling for the coupled thermo-mechanical processes and spalling phenomena in sp Pillar Stability Experiment (APSE)[J]. Journal of Rock Mechanics and Geotechnical Engineering,2013,01:58-72. 